\title{
Use of ultrasound guidance in central venous catheter placement by emergency physicians in Saudi Arabia
}

Zohair A. AlAseri, MD, FRCP, Reema M. AlHussein, MedicalStudent, MohammedA. Malabarey, MD, FRCP, BaderA. AlYahya, MD, FRCP, Faisal A. Al Moaiqel, Medical Student, Mariam A. Al Ansari, MD, FRCSI, Khaled N. Alrajhi, MD, FRCP.

\begin{abstract}

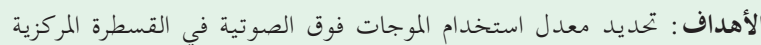
(EPs) لدى أطباء الطوارئ (USG_CVC)

المنهجية : هذه دراسة استعراضية استقصائية حول الملامح الديموغرافية لأطباء

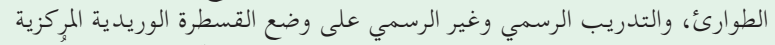

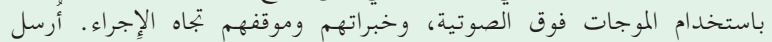

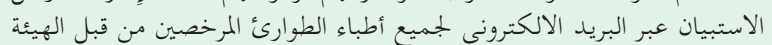

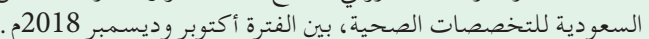

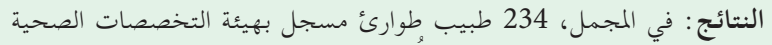

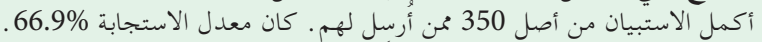

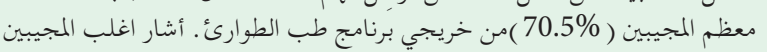

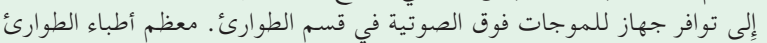

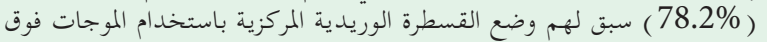

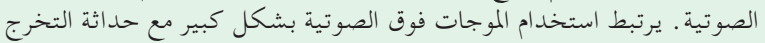

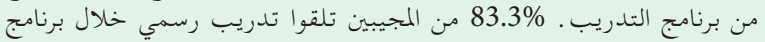

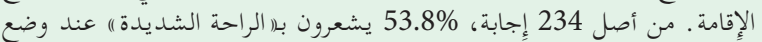

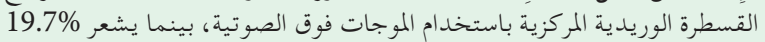

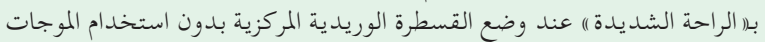

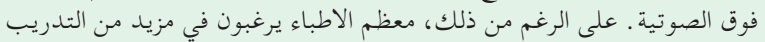

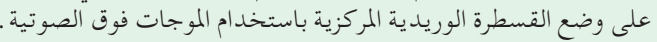

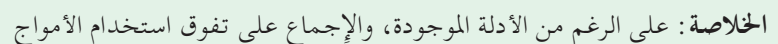

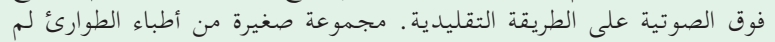

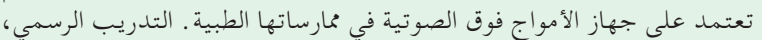

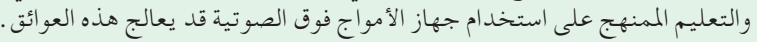

Objectives: To determine the ultrasound guidance for central venous catheter (USG-CVC) placement rate of emergency physicians (EPs) in Kingdom of Saudi Arabia.

Methods: A cross-sectional survey study regarding the respondents' demographic profiles, formal and informal training in USG-CVC placement, experiences, and attitudes towards the procedure was emailed to all EPs registered with the Saudi Commission for Health Specialties (SCFHS) between October and December 2018.
Results: In total, 234/350 SCFHS-registered EPs completed the survey; the response rate was $66.9 \%$. Most respondents $(70.5 \%)$ were board-certified in emergency medicine (EM). Ninety percent indicated that US device for CVC placement assistance was available. Most EPs $(78.2 \%)$ had performed USG-CVC placement; the US usage rate correlated significantly with recent graduation from residency $(p=0.048)$. In total, $83.3 \%$ received formal training during residency. Of the 234 respondents, $53.8 \%$ felt extremely comfortable with CVC placement with USG and $19.7 \%$ without USG $(p<0.01)$. Nevertheless, most respondents desired further USG-CVC training.

Conclusion: Despite existing evidence and a consensus on its superiority over the landmark technique, USGCVC placement has not been adopted by a small proportion of EPs into clinical practice. Formal training, education, and institutional provision of permanent onsite US machines may address any barriers.

Keywords: central venous catheters, ultrasonography, physicians, emergency medicine

Saudi Med J 2020; Vol. 41 (7): 698-702 doi: 10.15537/smj.2020.7.25162

From the Departments of Emergency Medicine and Critical Care (AlAseri), College of Medicine, King Saud University; from the Department of Emergency Medicine (Malabarey, Al Yahya), Medical City, King Saud University; from the College of Medicine (Al Hussein), Dar Aluloom University; from the College of Medicine (Al Moaiqel, Alrajhi), King Saud Bin Abdulaziz University for Health Sciences; from the Department of Emergency Medicine (Alrajhi), Health Affairs, Ministry of National Guard, Riyadh; and from the Department of Internal Medicine (Al Ansari), Intensive Care Unit, Al Imam Abdulrahman Bin Faisal Hospital, Health Affairs, Ministry of National Guard, Dammam, Kingdom of Saudi Arabia.

Received 10th February 2020. Accepted 10th June 2020.

Address correspondence and reprint request to: Dr. Zohair A. Al Aseri, College of Medicine, King Saud University, Riyadh, Kingdom of Saudi Arabia.E-mail: zalaseri@ksu.edu.sa

ORCID ID: orcid.org/0000-0001-9869-7544 
$\mathrm{T}$ he placement of a central venous catheter (CVC) has become an integral part of emergency medicine (EM) practice for critically ill patients. ${ }^{1,2}$ A previous observational cohort study reported a complication rate of $34 \%$ associated with CVC placement, with the majority of complications being related to placement failure. ${ }^{3}$ Moreover, a recent systematic review showed that the rate of adverse events such as arterial puncture, hematoma, and hemothorax resulting from CVC placement using the landmark technique was $13.5 \% .^{2}$ The utilization of ultrasonography during CVC placement is associated with a significant reduction in the relative risk of complications and an increase in the first-attempt success rate. ${ }^{2,4-7}$ In addition, real-time sonographic guidance for central venous access is strongly recommended by the European Federation of Societies for Ultrasound in Medicine and Biology (EFSUMB) guidelines as a key safety measure. ${ }^{8}$

Despite this evidence, there is limited incorporation of ultrasound guidance for central venous catheter (USG-CVC) placement in clinical practice by some emergency physicians (EPs). Indeed, in a recent study, $44 \%$ of respondents stated that they never used USG-CVC placement. ${ }^{9}$ Evidence suggests that EPs consider a lack of training to be a barrier to the widespread implementation of USG-CVC placement. ${ }^{10}$

The aim of this study is to survey practicing EPs in Kingdom of Saudi Arabia (KSA) with regard to the frequency of USG-CVC placement and factors that may be associated with its use.

Methods. A cross-sectional survey study targeting all EPs practicing in KSA was conducted. Participants were included if they are EPs practicing in KSA. For the purpose of this study, a physician would be considered an EP if they are in or have completed a residency program in EM or are licensed physicians classified by the Saudi Commission for Health Specialties as emergency physicians. Data was collected over a 2-month period from October to December of 2018. Emergency physicians at various hospitals and at various stages of their careers were invited to participate in the study. An email invitation containing the consent form and the survey material was sent via SurveyMonkey through the Saudi Commission for Health Specialties targeting 350 EPs. The sample size was calculated to

Disclosure. Authors have no conflict of interests, and the work was not supported or funded by any drug company. be 184 using a $95 \%$ confidence level, $5 \%$ confidence interval, and power of 80 .

The survey's face validity was established through a review of a group of board-certified, universityaffiliated EPs with several years of clinical experience. A small-scale feasibility/pilot study was conducted to determine the survey's reliability.

The survey contained direct questions to assess the frequency of ultrasound guidance for CVC placement. We hypothesize that factors associated with or barriers to USG be around demographics, training, clinical experience, attitudes, and resources. This was covered in the survey with questions on the demographic profiles of the respondents (gender, nationality, place of residence, type of hospital, number of years in practice, and number of clinical shifts), formal and informal training on USG-CVC placement, interest in further training, experience with CVCs, attitudes and comfort regarding USG-CVC placement. Likert scales were used to measure the participants' level of agreement regarding USG-CVC placement (1: strongly disagree to 5: strongly agree), their comfort in placing CVCs (0: extremely uncomfortable to 5: extremely comfortable), and their views and judgment toward the use of medical technology and uncertainty in diagnosis (1: strongly agree to 9: strongly disagree). To determine correlations with USG-CVC placement, the respondents were divided into 5 groups based on the percentage of CVCs that they had placed under US guidance: $0-20 \%, 21-40 \%, 41-60 \%, 61-80 \%$, and $81-100 \%$.

The data collected from SurveyMonkey was exported as a worksheet and analyzed using Statistical Package for Social Sciences (SPSS) version 23.0 (IBM Corp., Armonk, NY, USA). The results are expressed as numbers and percentages for categorical variables and as the mean and standard deviation for continuous variables. A Chi-square $\left(\chi^{2}\right)$ test was used to compare proportions between 2 groups. The Pearson correlation test was applied to determine the correlation between variables. Finally, univariate and multivariate regression analyses were performed to determine significant factors related to the non-use of USG-CVCs. To determine barriers carrying out USG-CVC placement on the basis, all relevant variables based on $p$-values $(p<0.05)$ were entered into a logistic regression model with USG-CVC placement as the dependent variable.

The study was approved by the Institutional Review Board (IRB), King Fahad Medical City at the Ministry of Health, Riyadh, KSA. It was found that the study compliant with the Principles of Helsinki Declaration. Participation in this study was voluntary 
and participants were informed about the aim, purpose, and procedure of the study. The participants were not offered incentives to participate in the study.

Results. In total, 350 emails were sent via the SCFHS to EPs, 234 of whom responded to the survey (response rate: $66.9 \%$ ). The majority of respondents (70.5\%) were board-certified in EM, and the remaining $29.5 \%$ were residents. Of the 234 respondents, the majority were practicing in a government or Ministry of Health hospitals (45.3\%) (Table 1).

Availability of US machines and use of USG-CVC placement technique. Most respondents (90.6\%) indicated that at least one US device for CVC placement assistance was available. One US machine was available for 54 respondents (23.1\%), 2 machines for 83 respondents $(35.5 \%), 3$ machines for 49 respondents (20.9\%), 4 machines for 20 respondents $(8.5 \%)$, and 6 or more machines for 7 respondents $(2.6 \%)$. Table 2

Table 1 - Demographic profiles of the emergency physicians surveyed $(\mathrm{N}=234)$.

\begin{tabular}{|c|c|}
\hline Demographic profiles & n $(\%)$ \\
\hline \multicolumn{2}{|l|}{ Gender } \\
\hline $\begin{array}{l}\text { Male } \\
\text { Female }\end{array}$ & $\begin{array}{r}177(75.6) \\
57(24.4)\end{array}$ \\
\hline \multicolumn{2}{|l|}{ Nationality } \\
\hline $\begin{array}{l}\text { Saudi } \\
\text { Non-Saudi }\end{array}$ & $\begin{array}{r}167(71.4) \\
67(28.6)\end{array}$ \\
\hline \multicolumn{2}{|l|}{ Place of residence } \\
\hline $\begin{array}{l}\text { Central region } \\
\text { Eastern region } \\
\text { Western region } \\
\text { Northern region } \\
\text { Southern region } \\
\text { Unspecified }\end{array}$ & $\begin{array}{rr}146 & (62.4) \\
18 & (7.7) \\
55 & (23.5) \\
1 & (0.4) \\
7 & (3.0) \\
7 & (3.0)\end{array}$ \\
\hline \multicolumn{2}{|l|}{ Type of hospital } \\
\hline $\begin{array}{l}\text { Government } \\
\text { Military } \\
\text { University } \\
\text { Private }\end{array}$ & $\begin{array}{r}106(45.3) \\
48(20.5) \\
55(23.5) \\
25(10.7)\end{array}$ \\
\hline \multicolumn{2}{|c|}{ Number of years practicing EM } \\
\hline $\begin{array}{l}\text { Currently still a resident } \\
<2 \text { years } \\
2-5 \text { years } \\
6-10 \text { years } \\
11-15 \text { years } \\
16-20 \text { years }\end{array}$ & $\begin{array}{r}40(17.1) \\
49(20.9) \\
72(30.8) \\
45(19.2) \\
19(8.1) \\
9 \quad(3.8)\end{array}$ \\
\hline \multicolumn{2}{|c|}{ Number of clinical shifts (average per month) in EM } \\
\hline $\begin{array}{l}1-2 \text { shifts } \\
3-5 \text { shifts } \\
6-10 \text { shifts } \\
11-15 \text { shifts } \\
>15 \text { shifts }\end{array}$ & $\begin{array}{rr}3 & (1.3) \\
7 & (3.0) \\
18 & 7.7) \\
43 & (18.4) \\
163 & (69.7)\end{array}$ \\
\hline
\end{tabular}

shows the percentage of CVC placements in which US guidance was used. Attending physicians supervised 155 (66.2\%) of the placements; other physicians, fellows, or residents supervised the remaining placements.

Formal and informal training. Some form of formal training in USG-CVC placement at various stages of residency training was received by 195 respondents $(83.3 \%)$. These included didactic or video-only training without hands-on training, experience with US-guided dynamic visualization without needle placement, and USG-CVC placement on a simulation model. Informal training modalities included hands-off observation, maneuvering the US device with or without insertion of a catheter. Thirty-nine (16.7\%) respondents did not have any type of formal training on USG-CVC placement (Table 3).

Attitudes and levels of comfort in placing CVCs with or without US guidance. More responders felt extremely comfortable with USG-CVC placement than with CVC placement without USG $(53.8 \%$ vs. $19.7 \%, p<0.01)$

Table 2 - The percentage of CVC placements conducted with USG.

\begin{tabular}{lc}
\hline Percentage of USG-CVC placement & $\mathbf{n}(\%)$ \\
\hline $0-20 \%$ & $36(15.4)$ \\
$21-40 \%$ & $12 \quad(5.1)$ \\
$41-60 \%$ & $28 \quad(1.0)$ \\
$61-80 \%$ & $40(17.0)$ \\
$81-100 \%$ & $115(49.1)$ \\
Ultrasound not available & $3(1.3)$ \\
\hline \multicolumn{2}{c}{ CVC: central venous catheter, USG: ultrasound guidance } \\
\hline
\end{tabular}

Table 3 - Formal and informal training on USG-CVC placement.

\begin{tabular}{lcc}
\hline Type of training & $\begin{array}{c}\text { Formal training } \\
(\mathbf{n}=195)\end{array}$ & $\begin{array}{c}\text { Informal training } \\
(\mathbf{n}=205)\end{array}$ \\
\hline $\begin{array}{l}\text { Didactic or video only without } \\
\text { hands-on training }\end{array}$ & $33(16.9)$ & $16(7.8)$ \\
$\begin{array}{l}\text { US-guided dynamic } \\
\text { visualization without needle } \\
\text { placement }\end{array}$ & $32(16.4)$ & $32(15.6)$ \\
$\begin{array}{l}\text { US-guided placement on } \\
\text { simulation model }\end{array}$ & $130(66.7)$ & $157(76.6)$ \\
\hline \multicolumn{1}{c}{ Values are expressed as number and percentage (\%). } \\
\multicolumn{1}{c}{ USG-CVC: ultrasound guided central venous catheter } \\
\hline
\end{tabular}


(Table 4). The majority of respondents strongly agree/ agree that USG-CVC placement is easier to perform, is faster, reduces mechanical complications, results in fewer placement failures, and is useful for patients with difficult landmarks (Table 5).

Correlates of USG-CVC placement. Most EPs (78.2\%) had performed USG-CVC placement. Ultrasound guidance for central venous catheter placement correlated significantly with fewer years from graduation of residency $(\mathrm{r}=0.130, p=0.048)$, having attended formal courses on their own ( $\mathrm{r}=0.196$, $p=0.003$ ) and courses provided by the hospital

Table 4 - Levels of comfort in placing central venous catheter with and without USG.

\begin{tabular}{lccc}
\hline Level of comfort & With USG & Without USG & $P$-value \\
\hline Extremely comfortable & $126(53.8)$ & $46(19.7)$ & $<0.001$ \\
Moderately comfortable & $62(26.5)$ & $80(34.2)$ & 0.0703 \\
Mildly comfortable & $13(5.6)$ & $26(11.1)$ & 0.0300 \\
Mildly uncomfortable & $12(5.1)$ & $31(13.2)$ & 0.0024 \\
Moderately uncomfortable & $7(3.0)$ & $24(10.3)$ & $<0.001$ \\
Extremely uncomfortable & $14(6.0)$ & $27(11.5)$ & 0.0332 \\
\hline
\end{tabular}

Values are presented as number and percentage (\%). USG - ultrasound guidance $(\mathrm{r}=0.161, p=0.014)$, the availability of a portable US machine to assist EPs in CVC placement $(r=0.170$, $p=0.009$ ), comfort in placing CVCs with US guidance $(\mathrm{r}=0.253, p<0.001)$, and perceptions that USG-CVC placement is faster $(\mathrm{r}=0.272, p<0.001)$, reduces mechanical complications $(\mathrm{r}=0.297, p<0.001)$ and infectious complications $(\mathrm{r}=0.172, p=0.008)$, results in fewer placement failures $(\mathrm{r}=0.355, p<0.001)$, is useful when the landmark method is unsuccessful $(r=0.175$, $p=0.007$ ), is useful for patients with coagulopathy $(\mathrm{r}=0.154, p=0.018)$, is more convenient $(\mathrm{r}=0.277$, $p<0.001)$, and is cost effective $(r=0.237, p<0.001)$.

Discussion. The use of USG-CVCs has been the subject of several research papers and has been found to decrease morbidity and complications caused by the traditional landmark method..$^{2-6,11-13}$ Our survey showed that most EPs in KSA agree with the published literature. Despite these findings, $21.8 \%$ of the respondents had never/seldom used the US in CVC placement. In a cross-sectional survey of practicing EPs in the United States, $44 \%$ had never used US guidance in placing CVCs. ${ }^{9}$ However, fewer physicians in our survey had never/seldom used USG in CVC placement than in previous studies. Based on the literature, we believe that every CVC should be inserted under USG and that every effort should target barriers to US use in CVC placement. Several barriers to USG-CVC placement have been identified. Matera et al, ${ }^{14}$ reported common

Table 5 - The respondents' levels of agreement on the advantage of using USG over the landmark method for CVC placement.

\begin{tabular}{|c|c|c|c|c|c|c|}
\hline \multirow{3}{*}{$\begin{array}{l}\text { USG-CVC placement } \\
\text { Is easy to use }\end{array}$} & \multicolumn{5}{|c|}{ Levels of agreement } & \multirow{2}{*}{$\begin{array}{c}P \text {-value } \\
\text { (strongly agree/agree } \\
\text { versus strongly disagree/ } \\
\text { disagree) }\end{array}$} \\
\hline & \multirow{2}{*}{$\begin{array}{l}\begin{array}{c}\text { Strongly } \\
\text { agree }\end{array} \\
125(53.4)\end{array}$} & \multirow{2}{*}{$\begin{array}{l}\text { Agree } \\
68(29.1)\end{array}$} & \multirow{2}{*}{$\begin{array}{l}\text { Neutral } \\
29(12.4)\end{array}$} & \multirow{2}{*}{$\begin{array}{l}\text { Disagree } \\
\\
8 \quad(3.4)\end{array}$} & $\begin{array}{l}\text { Strongly } \\
\text { disagree }\end{array}$ & \\
\hline & & & & & $4 \quad(1.7)$ & \\
\hline Is faster & $85(36.3)$ & $56(23.9)$ & $48(20.5)$ & $36(15.4)$ & $9 \quad(3.8)$ & \\
\hline Reduces mechanical complications & $133(56.8)$ & $81(34.6)$ & $19(8.1)$ & $1 \quad(0.4)$ & - & \\
\hline Reduces infectious complications & $45(19.2)$ & $59(25.2)$ & $88(37.6)$ & $37(15.8)$ & $5(2.1)$ & \\
\hline Results in fewer placement failures & $114(48.7)$ & $93(39.7)$ & $24(10.3)$ & $3(1.3)$ & - & \\
\hline Is useful for patients lacking good landmarks & $157(67.1)$ & $63(26.9)$ & $14(6.0)$ & - & - & \\
\hline Is useful when landmark is unsuccessful & $144(61.5)$ & $76(32.5)$ & $13(5.6)$ & - & $1 \quad(0.4)$ & $<0.001$ \\
\hline Is useful for patients with coagulopathy & $119(50.9)$ & $64(27.4)$ & $43(18.4)$ & $7(3.0)$ & $1 \quad(0.4)$ & \\
\hline Is less convenient & $23(9.8)$ & $45(19.2)$ & $60(25.6)$ & $67(28.6)$ & $39(16.7)$ & \\
\hline Is not needed (more comfortable with landmark method) & $6(2.6)$ & $19(8.1)$ & $49(20.9)$ & $87(37.2)$ & $73(31.2)$ & \\
\hline Will result in loss of their skills & $11(4.7)$ & $30(12.8)$ & $55(23.5)$ & $97(41.5)$ & $41(17.5)$ & \\
\hline Is beneficial for randomized trials & $15(6.4)$ & $20 \quad(8.5)$ & $77(32.9)$ & $70(29.9)$ & $52(22.2)$ & \\
\hline Is not cost-effective & $16(6.8)$ & $28(12.0)$ & $54(23.1)$ & $79(33.8)$ & $57(24.4)$ & \\
\hline
\end{tabular}


barriers to routine US use in CVC placement, namely, not having completed a US course and perceiving the procedure as time-consuming. In another survey, Scholten et al, ${ }^{15}$ found that working in a non-academic hospital and more years of experience were barriers to USG-CVC placement. Two other surveys showed that insufficient training and the limited availability of equipment are barriers to US use. ${ }^{9,16}$ In accordance with previous surveys, our respondents identified the lack of formal training and unavailability of a US machine as barriers to USG-CVC placement.

Study limitations. The limitation of this study is that the survey responses were self-reported; indeed, the responses may not reflect the true competence of the respondents. Additionally, the results may have been influenced by bias, and the questions may have been unclear to some of the respondents. Furthermore, our results may not be generalizable because the majority of our respondents were in their early years of practice.

In conclusion, we were able to highlight the use of the USG-CVC placement technique by EPs, the nature and benefits of training on USG-CVC placement, and the respondents' perceptions and attitudes toward CVC placement.

Despite existing evidence and a consensus regarding the superiority of USG-CVC placement over the landmark technique, a small proportion of EPs have been unable to translate evidence into clinical practice. Future studies on the effectiveness of current training and impact of various forms of formal or informal education on adoption and best practices for institutional provisions for placement of US machines on-site may address any barriers.

Acknowledgment. The authors gratefully acknowledge American Journal Editors (https://www.aje.com) for the English language editing.

\section{References}

1. Oulego-Erroz I, González-Cortes R, García-Soler P, BalaguerGargallo M, Frías-Pérez M, Mayordomo-Colunga J, et al. Ultrasound-guided or landmark techniques for central venous catheter placement in critically ill children. Intensive Care Med 2018; 44: 61-72.

2. Brass P, Hellmich M, Kolodziej L, Schick G, Smith AF. Ultrasound guidance versus anatomical landmarks for internal jugular vein catheterization. Cochrane Database Syst Rev 2015; 1: CD006962.
3. Eisen LA, Narasimhan M, Berger JS, Mayo PH, Rosen MJ, Schneider RF. Mechanical complications of central venous catheters. J Intensive Care Med 2006; 21: 40-46.

4. Wu SY, Ling Q, Cao LH, Wang J, Xu MX, Zeng WA. Real-time two-dimensional ultrasound guidance for central venous cannulation: a meta-analysis. Anesthesiology $2013 ; 118$ : 361-375.

5. Palepu GB, Deven J, Subrahmanyam M, Mohan S. Impact of ultrasonography on central venous catheter insertion in intensive care. Indian J Radiol Imaging 2009; 19: 191-198.

6. Lau CS, Chamberlain RS. Ultrasound-guided central venous catheter placement increases success rates in pediatric patients: a meta-analysis. Pediatr Res 2016; 80: 178-184.

7. Froehlich CD, Rigby MR, Rosenberg ES, Li R, Roerig PJ, Easley KA, et al. Ultrasound-guided central venous catheter placement decreases complications and decreases placement attempts compared with the landmark technique in patients in a pediatric intensive care unit. Crit Care Med 2009; 37: 1090-1096.

8. Jenssen C, Brkljacic B, Hocke M, Ignee A, Piscaglia F, Radzina $\mathrm{M}$, et al. EFSUMB guidelines on interventional ultrasound (INVUS), Part VI - ultrasound-guided vascular interventions. Ultraschall Med 2016; 37: 473-476.

9. Buchanan MS, Backlund B, Liao MM, Sun J, Cydulka RK, Smith-Coggins R, et al. Use of ultrasound guidance for central venous catheter placement: survey from the american board of emergency medicine longitudinal study of emergency physicians. Acad Emerg Med 2014; 21: 416-421.

10. Backlund BH, Hopkins E, Kendall JL. Ultrasound guidance for central venous access by emergency physicians in colorado. West J Emerg Med 2012; 13: 320-325.

11. Leung J, Duffy M, Finckh A. Real-time ultrasonographicallyguided internal jugular vein catheterization in the emergency department increases success rates and reduces complications: a randomized, prospective study. Ann Emerg Med 2006; 48: 540-547.

12. Theodoro D, Bausano B, Lewis L, Evanoff B, Kollef M. A descriptive comparison of ultrasound-guided central venous cannulation of the internal jugular vein to landmark-based subclavian vein cannulation. Acad Emerg Med 2010; 17: 416-422.

13. Saugel B, Scheeren TWL, Teboul JL. Ultrasound-guided central venous catheter placement: a structured review and recommendations for clinical practice. Crit Care 2017; 21: 225.

14. Matera JT, Egerton-Warburton D, Meek R. Ultrasound guidance for central venous catheter placement in Australasian emergency departments: potential barriers to more widespread use. Emerg Med Australas 2010; 22: 514-523.

15. Scholten HJ, Ten Bloemendal E, Botter B, Korsten HHM, Bouwman RA. Barriers to ultrasound guidance for central venous access: a survey among Dutch intensivists and anaesthesiologists. J Clin Monit Comput 2019; 33: 1023-1031.

16. Zaver F, Boniface K, Wachira B, Wanjiku G, Shokoohi H. International scope of emergency ultrasound: Barriers in applying ultrasound to guide central line placement by providers in Nairobi, Kenya. Emerg Med Int 2018; 2018: 7328465. 